\title{
IMPACTOS FINANCEIROS DOS GASTOS DAS MEDIDAS DE GESTÃO AMBIENTAL EM UMA UNIDADE DE ABASTECIMENTO DE POSTO DE COMBUSTÍVEL
}

\author{
Francieli Rosa de Franceschi ${ }^{1}$, Vanessa de Matos da Costa ${ }^{2}$, Jaqueline Carla Guse ${ }^{3}$, \\ Luiz Antonio Rossi de Freitas ${ }^{4}$, Marivane Vestena Rossato ${ }^{5}$, \\ Daniel Benitti Lorenzett ${ }^{6}$, Andrea Cristina Dörr ${ }^{7}$ \\ ${ }^{1}$ francieli@hotmail.com, ${ }^{2}$ vanessa@hotmail.com, ${ }^{3}$ drjaquelineguse@ hotmail.com, ${ }^{4}$ luizrf@terra.com.br, \\ ${ }^{5}$ marivavest@gmail.com, ${ }^{6}$ dlorenzett@gmail.com, ${ }^{7}$ andreadoerr@yahoo.com.br
}

\section{RESUMO}

O meio ambiente é um recurso indispensável à sobrevivência da humanidade, como também são indispensáveis certas atividades econômicas, sendo de difícil conciliação uma convivência pacífica entre ambas. Sabe-se da preocupação crescente em propor um desenvolvimento econômico contemplando questões relacionadas ao meio ambiente, de forma a promover condições ambientais básicas, não agredindo a natureza e o local onde tais empreendimentos são instalados. Nesse sentido, os postos de combustíveis, por serem caracterizados pelo desenvolvimento de atividades de alto risco para o meio ambiente, devem investir em proteção ambiental de forma a tornar sua atividade menos agressiva possível. Qualquer medida de gestão ambiental adotada a fim de preservar o meio ambiente envolve o consumo de recursos, que necessitam ser controlados e corretamente contabilizados. Assim sendo, é dever da contabilidade identificar e avaliar os eventos econômico-financeiros relacionados ao meio ambiente, capazes de afetar o estado patrimonial e o resultado das entidades. Este estudo buscou identificar as medidas de gestão ambiental implantadas pela Cooperativa dos Condutores Autônomos de Veículos Rodoviários de Santa Maria/RS, além de analisar os gastos associados às ações de gestão ambiental. Foi empregada a técnica da observação aliada à técnica da entrevista estruturada. Os resultados revelaram que os custos ambientais tiveram uma representatividade negativa para a empresa, ou seja, ao invés de contribuir para a manutenção e o crescimento da empresa, representaram um sacrifício econômico, visto que não se diluíram no volume das receitas do decorrer do exercício.

PALAVRAS-CHAVE: Contabilidade Ambiental. Gastos Ambientais. Comércio de Combustíveis.

\section{ABSTRACT}

The environment is an indispensable resource for human survival, as well as certain economic activities are essential, and difficult to reconcile a peaceful coexistence between the two. It is of growing concern in proposing an economic development covering issues related to the environment, to promote basic environmental conditions, not attacking the nature and place where such ventures are installed. Accordingly, the gas stations because they are characterized by the development of high-risk activities for the environment, should invest in environmental protection in order to make their activity less aggressive as possible. Any measure adopted environmental management in order to preserve the environment involves the consumption of resources, which need to be controlled and properly accounted for. Therefore, it is the duty of accounting to identify and assess the economic and financial events related to the environment, 
can affect the outcome of state assets and entities. This study sought to identify the environmental management measures implemented by the Cooperative of Autonomous Road Vehicles Drivers of Santa Maria, and analyzing costs associated with environmental management actions. Technique was employed for observation combined with the structured interview technique. The results revealed that the environmental costs had a negative representative for the company, in other words, instead of contributing to the maintenance and growth of the company, represented an economic sacrifice, as it is not diluted in the volume of revenues during the year.

KEYWORDS: Environmental Accounting. Environmental expenditures. Trade in fuels.

\section{INTRODUÇÃO}

O meio ambiente é um recurso indispensável à sobrevivência da humanidade, como também são indispensáveis certas atividades econômicas, sendo de difícil conciliação uma convivência pacífica entre ambas.

Sabe-se da preocupação crescente em propor um desenvolvimento econômico contemplando questões relacionadas ao meio ambiente, de forma a promover condições ambientais básicas, não agredindo a natureza e o local onde tais empreendimentos são instalados. Assim, os esforços feitos para promover a melhoria dos níveis de poluição, seja associada ao ar, água, solo e a outros compartimentos ambientais, tornam-se fundamentais.

Neste sentido, a gestão ambiental tem como princípio alinhar as atividades humanas a fim de que estas gerem o menor impacto possível sobre o meio ambiente. $E$ isto vai desde a escolha das melhores técnicas até o cumprimento da legislação para o destino correto de recursos humanos e financeiros. Assim, pode-se entender por gestão ambiental a consequência natural da evolução do pensamento da humanidade em relação à utilização dos recursos naturais de um modo mais sábio, onde se deve utilizá-los de forma sustentável, sempre numa proporção inferior a capacidade de reposição natural do meio, investindo em proteção e preservação ambiental, para minimizar os impactos já causados.

Os benefícios dessa gestão ambiental são evidenciados por Tinoco (2004), iniciando pela redução dos riscos ambientais da atividade (emissões, derrames, acidentes, e outros), passando pelo aumento na motivação dos colaboradores, pois promove a delegação de responsabilidades e autoridades. E em última análise, transmitindo à sociedade uma melhoria da imagem da empresa, desde que explorada corretamente pelo marketing ambiental.

Ressalta-se que quando da ausência de medidas de gestão ambiental, as entidades podem incorrer em impactos ambientais, prejudicando não só o meio ambiente, mas também toda forma de vida que sobrevive dele, especialmente os seres humanos.

Nesse contexto, as administrações públicas em conjunto com organizações não governamentais vêm buscando estabelecer normas e procedimentos mais seguros e adequados às atividades econômicas, principalmente aquelas consideradas potencialmente poluidoras. Os postos de combustíveis se enquadram nestas normas, sendo caracterizados pelo desenvolvimento de atividades de alto risco para o meio ambiente que, em acordo com a Resolução no 237/97 do Conselho Nacional do Meio Ambiente (CONAMA), deve investir em proteção ambiental tendo que se adequar de forma a tornar sua atividade menos agressiva possível.

Segundo Lorenzett et al. (2010), a gestão ambiental em postos de combustíveis, pode ser entendida como as medidas realizadas pelo estabelecimento que contribuem para a proteção, 
preservação e recuperação ambiental, que vão desde a implantação de instalações mais seguras até a manutenção de áreas verdes de preservação ambiental.

Esses atos necessários para preservar o meio ambiente envolvem o consumo de recursos, que necessitam ser controlados e corretamente contabilizados. Segundo Tinoco (2004, p.166), a contabilidade ambiental "serve para evidenciar e espelhar a relação das empresas e da nação com o meio ambiente". Ainda para Tinoco (2004), a contabilidade ambiental é o registro do patrimônio ambiental (bens, direitos e obrigações ambientais) de determinada entidade, e suas respectivas alterações expressos monetariamente. Assim sendo, é dever da contabilidade identificar e avaliar os eventos econômico-financeiros relacionados ao meio ambiente, capazes de afetar o estado patrimonial e o resultado das entidades.

Nesse contexto, o presente estudo teve como foco identificar as medidas de gestão implantadas pela Cooperativa dos Condutores Autônomos de Veículos Rodoviários e analisar os impactos financeiros de tais medidas. $O$ assunto em questão surge devido à necessidade de se pesquisar os gastos associados à adoção de medidas de gestão ambiental num posto de combustível, tema de fundamental importância, frente ao anseio global por sustentabilidade.

Nesse sentido, a contabilidade também pode dar sua contribuição, pois é responsável pelos registros dos valores associados às medidas de proteção e preservação ambiental, adotadas pelo segmento, por motivo da obrigatoriedade expressa na legislação vigente.

Os postos de combustíveis, por serem considerados potencialmente poluidores, devem se adequar às exigências legais, especialmente à Resolução CONAMA no 237/97, a qual estabelece que toda instalação e sistema de armazenamento de derivados de petróleo e outros combustíveis, que configuram-se como empreendimentos potencialmente ou parcialmente poluidores e geradores de acidentes ambientais, estão sujeitos ao licenciamento ambiental.

Em função do grande volume de recursos associados à adoção de medidas de gestão ambiental, torna-se importante controlá-los e avaliá-los, pois a partir do registro e controle contábil dos fatos associados a tais medidas, os gestores podem se valer de informações quanto a sua representatividade econômico-financeira para o processo de gestão da entidade.

\section{METODOLOGIA}

O procedimento metodológico é formado por uma série de regras com a finalidade de resolver determinado problema, explicando um fato por meio de hipóteses ou teorias que devem ser testadas experimentalmente podendo ser comprovadas ou rejeitadas. Sendo assim, nesta seção são expostos os métodos e técnicas utilizados no desenvolvimento do estudo, como também, descritos os passos operacionais a serem realizados.

No que tange à abordagem do problema, a pesquisa é considerada qualitativa, tendo em vista que foi desenvolvida mediante observação e descrição do tema, sem utilizar procedimentos estatísticos para a análise do problema. Para Beuren et al. (2006), a principal diferença entre uma abordagem qualitativa e quantitativa reside no fato de a abordagem qualitativa não empregar um instrumento estatístico, como base do processo de análise do problema. Na abordagem qualitativa não se pretende numerar ou medir unidades ou categorias homogêneas.

Segundo Beuren et al. (2006, p. 92), "cabe lembrar que apesar de a Contabilidade lidar intensamente com números, ela é uma ciência social e não uma ciência exata como alguns poderiam pensar, o que justifica a relevância do uso da abordagem qualitativa". 
Quanto aos objetivos, a presente pesquisa é classificada como descritiva. De acordo com Cervo e Bervian (2002, p.66) este tipo de pesquisa: "observa, registra, analisa e correlaciona fatos ou fenômenos (variáveis) sem manipulá-los".

Sendo assim, além de registrar e analisar os fenômenos estudados, procura identificar suas causas. Relacionado à pesquisa descritiva, Gil (2007, p.42), afirma ser o objetivo primordial dessa pesquisa "a descrição das características de determinada população ou fenômenos ou, o estabelecimento de relações entre variáveis".

No que se refere aos procedimentos técnicos, esta pesquisa fez uso de três Procedimentos. Primeiramente utilizou-se o recurso da pesquisa bibliográfica a qual foi fonte de embasamento para o início dos estudos. Posteriormente, pesquisa documental e, depois partiu-se, para o estudo de caso.

A pesquisa documental é definida por, Marconi e Lakatos (2005, p.176) como "a pesquisa que possui como característica principal ter a fonte de coleta de dados restrita a documentos, escritos ou não, criando o que se denomina de fontes primárias, ou seja, as que ainda não receberam tratamento". Nessa etapa da pesquisa foram analisados documentos contábeis da empresa estudada, como o Balanço Patrimonial (BP), a Demonstração de Sobras e Perdas do Exercício e os relatórios auxiliares.

O estudo de caso foi realizado no posto de combustíveis, denominado Cooperativa dos Condutores Autônomos de Veículos Rodoviários de Santa Maria (Coopaver), localizado na cidade de Santa Maria/RS.

Para a coleta de dados, foi considerado o procedimento da observação e da entrevista estruturada. Foi possível enquadrar nesse procedimento, a observação do funcionamento do estabelecimento e os procedimentos inerentes à atividade de posto de combustível, da forma como ocorre a interação da entidade com o meio ambiente. Segundo Martins (2006), o procedimento da observação envolve a percepção sensorial do pesquisador, sendo altamente subjetivo, pois por muitas vezes, ainda que de forma involuntária, a concepção do pesquisador poderá influir em suas anotações.

Já a entrevista estruturada, segundo Marconi e Lakatos (2005), é uma forma de coleta de dados onde é realizada uma entrevista com indivíduos pré-selecionados e segue-se um cronograma de perguntas pré-estabelecidas. Assim, quando entrevistada mais de uma pessoa, pode-se ter um parâmetro para comparação das diversas respostas resultantes das mesmas perguntas.

A escolha do período para o desenvolvimento do estudo compreende aos exercícios de 2009 e 2010. No ano de 2009 identificou-se que a empresa já vinha investindo em preservação e preocupação ambiental. Já a escolha de 2010, foi em função do adiantamento da distribuidora Ipiranga para a empresa com finalidade de ser usado em prol de melhorias em questões ambientais as quais foram realizadas no ano de 2011. E para uma melhor análise dos dados foram utilizados esses dois períodos. 


\section{RESULTADOS E DISCUSSÕES}

\section{Ambiente da Pesquisa}

Em 1977, o Brasil passou por uma crise de racionamento de combustíveis, onde por determinação do governo federal nos finais de semana e nos feriados os postos eram obrigados a fechar. E uma das categorias mais prejudicadas, com isso, foram os taxistas, que se viam obrigados a armazenar gasolina e álcool nas suas garagens para não deixar de trabalhar.

Diante desta crise, foi criada, durante uma assembleia, a Cooperativa dos Condutores Autônomos de Veículos Rodoviários de Santa Maria (Coopaver). A Cooperativa teve sua origem no Sindicato dos Condutores Autônomos de Veículos Rodoviários e Transportes Autônomos de Bens de Santa Maria e Região (Sincaver), hoje Sinditáxi.

A Coopaver foi idealizada pelo taxista Mariano Costa e o grupo começou com 101 associados (designados sócios fundadores). Em 1990, a cooperativa iniciou a venda de combustíveis para a comunidade em geral, na época, com a bandeira Atlantic, que passou a ser Companhia Ipiranga de Petróleo, e hoje pertencente ao Grupo Ultra.

Ao longo dessas três décadas, a Cooperativa foi crescendo, tanto em número de sócios, que hoje são em 244 associados, quanto em serviços prestados à categoria e ao público em geral. Atualmente, junto ao posto, situado na Avenida Nossa Senhora Medianeira com a Rua Floriano Peixoto, funciona a loja de auto peças de uso dos taxistas e também aberto ao público.

Os taxistas, também contam com serviços de oficina mecânica, borracharia e oficina de taxímetros, sem custo para os associados, além de três veículos equipados com taxímetros, comprados pela cooperativa, que estão disponíveis para substituir qualquer carro da frota em caso de acidente ou problema mecânico. Os chamados carros-reservas podem ser solicitados por qualquer associado que precise ficar com táxi parado por mais de 48 horas, impedindo assim prejuízo financeiro para o dono do veículo.

O crescimento da Coopaver exigiu a contratação de novos funcionários, gerando assim empregos na comunidade santa-mariense. Hoje, 46 colaboradores trabalham na Cooperativa, que tem a cada três anos eleição para uma nova diretoria, onde seis pessoas são escolhidas, em assembléia, pelos taxistas.

Por ser referência na cidade em volume de vendas, a Cooperativa foi vencedora, por seis anos consecutivos, em premiações pela qualidade de seus produtos e excelência em atendimento.

\section{Levantamento das ações de gestão ambiental}

Com o uso da técnica da observação da exposição do Diretor Comercial da Coopaver, e em conjunto com a entrevista estruturada foi observado que o posto estudado adotou todas as medidas exigidas pelos órgãos fiscalizadores na questão ambiental desde quando passaram a ser exigidas.

O posto adotou como medida de controle ambiental tanques ecológicos anticorrosivos, com o intuito de evitar possíveis vazamentos de combustíveis. Além dessa medida, mantém três poços de monitoramento na área dos tanques subterrâneos, onde são retiradas semestralmente amostras das águas subterrâneas para verificar seu grau de pureza, de forma a assegurar que essas águas não serão contaminadas. Como adoção complementar de medidas ambientais há o controle do volume de combustível que entra e que sai, através do Livro de Movimentação de Combustível (LMC). Esse livro não foi adotado por exigência legal, mas sim como ferramenta para monitoramento de vazamentos de combustíveis, baseado no pressuposto de que todo combustível que entra deve sair. Caso o volume de saída de combustível seja inferior ao volume 
de entrada, pode haver vazamentos, que podem ser identificados em tempo hábil a fim de impedir maiores danos.

As três bombas utilizadas no abastecimento dos veículos são eletrônicas, o que permite maior precisão no abastecimento. Essas bombas possuem, em seus bicos, um sensor que aciona quando da presença de calor excessivo ou do contato com o combustível, quando o tanque encontra-se cheio, impedindo que ocorra o derrame de combustível e também possíveis explosões. Conta-se ainda, com um sistema interno que impede a volta de combustível para a bomba, não permitindo, em caso de incêndio que o fogo atinja maiores proporções, e reduzindo a probabilidade de explosões.

Os frentistas utilizam para realizar o abastecimento, uma flanela, com a qual limpam o bico da bomba quando da retirada do veículo no término do abastecimento. Essa prática, evita o gotejamento de combustível tanto no veículo como no piso do estabelecimento.

Nas atividades de troca de óleo, filtro e lubrificação, todo o óleo queimado retirado de veículos é conduzido ao tanque (reservatório subterrâneo de óleo queimado) de forma canalizada, para uma futura coleta por empresa especializada, sendo que os demais resíduos, como: flanelas, estopas, embalagens e filtros usados, são devidamente armazenados para uma também posterior coleta por empresas especializadas, através da cadeia de logística reversa desses materiais.

Toda a região das atividades do posto é cercado por canaletas, que são interligadas a caixa separadora de água e óleo e servem para condução dos efluentes líquidos, gerados pela atividade, para a caixa separadora, onde recebem o devido tratamento.

Outra medida de gestão ambiental é o aproveitamento da água da chuva e o tratamento dos efluentes líquidos, onde são retirados da água todos os resíduos químicos antes de sua devolução para a natureza, através de duas caixas separadoras de água e óleo.

A realização de treinamento aos colaboradores é realizada pela empresa Geoambiental, com atividades voltadas para operação, manutenção e resposta a acidentes. Onde frentistas são treinados para os procedimentos corretos no desenvolvimento das atividades. Este treinamento ocorre anualmente com todo o pessoal do posto para operação, manutenção e resposta a acidentes.

As medidas de gestão ambiental adotadas, como podem ser observadas na Figura 1, são ações de controle e prevenção ambiental, e em geral estão intimamente relacionadas às atividades desenvolvidas no posto de combustível. 


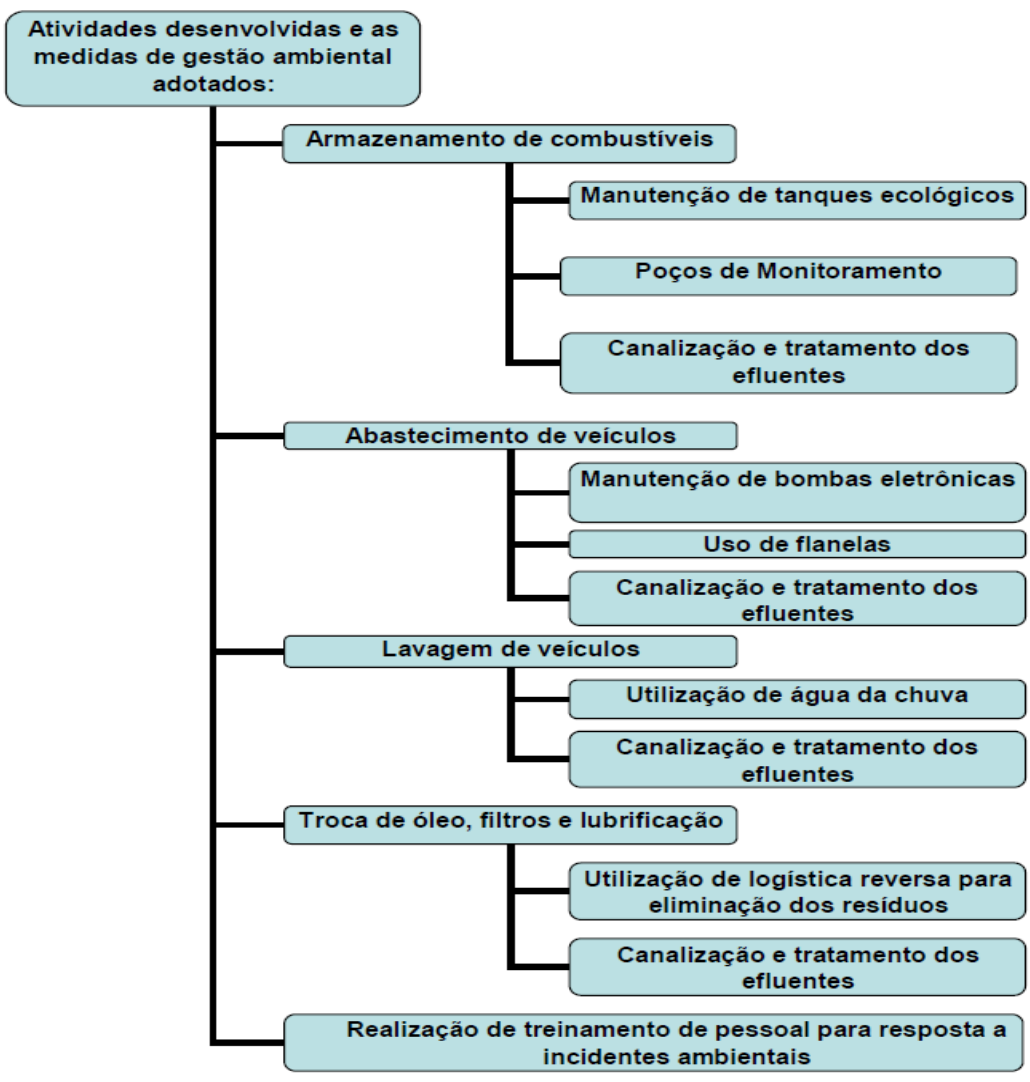

Figura 1 - Organograma de gestão ambiental desenvolvido por atividade.

Fonte: Dados da pesquisa.

\section{Gastos associados às ações de gestão ambiental}

Os gastos ambientais incorridos pela Cooperativa para se manter de acordo com a legislação aplicada e poder desenvolver a atividade estão apresentados no Quadro 1.

\begin{tabular}{|c|c|}
\hline \multicolumn{2}{|c|}{ armazenamento de combustíveis); } \\
\hline b) & Gastos com manutenção das válvulas e suspiros dos tanques subterrâneos; \\
\hline c) & Gastos na manutenção das bombas eletrônicas de abastecimento; \\
\hline \multicolumn{2}{|c|}{ gotejamento de combustível na pista e nos veículos; } \\
\hline \multicolumn{2}{|c|}{ estocagem dessa água; } \\
\hline f) & Gastos com a manutenção de uma caixa separadora de água e óleo; \\
\hline \multicolumn{2}{|c|}{$\begin{array}{l}\text { g) Gasto mensal com o recolhimento de resíduos, ou seja, com os canais de logística reversa, } \\
\text { para o recolhimento de óleo queimado, recolhimento de embalagens de lubrificantes e recolhimento de } \\
\text { filtros usados, estopas e flanelas e do lodo gerado na caixa separadora; }\end{array}$} \\
\hline h) & Gastos com o pagamento de taxa a órgão ambiental; \\
\hline i) & Gastos no treinamento de pessoal para resposta a incidentes ambientais; \\
\hline j) & Gastos com análises laboratoriais para verificação da qualidade das águas subterrâneas; \\
\hline k) & Gastos com a manutenção dos poços de monitoramento. \\
\hline
\end{tabular}

Quadro 1. Gastos ambientais realizados pela cooperativa. Fonte: Dados da pesquisa. 
Através da busca dos dados nos documentos contábeis da empresa, procurou-se identificar os gastos ambientais classificados em despesas e custos, nos anos de 2009 e 2010. Nos Quadros 2 e 3 apresentam-se individualmente identificados e separados esses gastos ambientais, de acordo com sua respectiva destinação.

\begin{tabular}{|c|c|c|}
\hline CUSTOS AMBIENTAIS & 2010 & 2009 \\
\hline Utilização de flanelas & 344,40 & - \\
\hline Treinamento de pessoal & $1.268,00$ & $1.012,00$ \\
\hline $\begin{array}{l}\text { Manutenção das válvulas e suspiros dos tanques } \\
\text { subterrâneos }\end{array}$ & 600,00 & 90,00 \\
\hline $\begin{array}{l}\text { Manutenção da caixa separadora de água e óleo e } \\
\text { poços de monitoramento }\end{array}$ & 300,00 & 796,80 \\
\hline $\begin{array}{l}\text { Manutenção das bombas eletrônicas de abastecimento } \\
\text { e monitoramento dos tanques ecológicos }\end{array}$ & 453,00 & 339,91 \\
\hline $\begin{array}{c}\text { Recolhimento de resíduos, óleo queimado } \mathrm{e} \\
\text { embalagens de lubrificantes }\end{array}$ & $1.352,50$ & 655,00 \\
\hline $\begin{array}{l}\text { Análises laboratoriais da qualidade das águas } \\
\text { subterrâneas }\end{array}$ & $1.780,50$ & 262,50 \\
\hline TOTAL & $6.098,40$ & $3.156,21$ \\
\hline
\end{tabular}

Quadro 2 - Custos ambientais Fonte: Dados da pesquisa.

\begin{tabular}{|c|c|c|}
\hline DESPESAS AMBIENTAIS & $\mathbf{2 0 1 0}$ & $\mathbf{2 0 0 9}$ \\
\hline $\begin{array}{c}\text { Pagamento de taxas a órgãos públicos e } \\
\text { taxas de alvarás ambientais }\end{array}$ & $7.953,31$ & $10.502,64$ \\
\hline TOTAL & $\mathbf{7 . 9 5 3 , 3 1}$ & $\mathbf{1 0 . 5 0 2 , 6 4}$ \\
\hline
\end{tabular}

Quadro 3 - Despesas ambientais

Fonte: Dados da pesquisa.

Em relação à análise dos impactos financeiros, constatou-se que as despesas ambientais tiveram maior impacto sobre a receita líquida do que os custos, e isso pode ser visualizado através da Figura 2. As despesas tiveram um impacto em 2009 de 0,08\% em relação a receita e de 0,06\% em 2010, diminuindo de um ano para outro. Já os custos foram menos marcantes, visto que em 2009 tiveram 0,02\% e em 2010 um percentual de 0,05\% em relação à receita. Esse fator se deve ao alto valor pago de taxas aos órgãos públicos e taxas de alvarás ambientais que são classificados como despesa ambiental. 


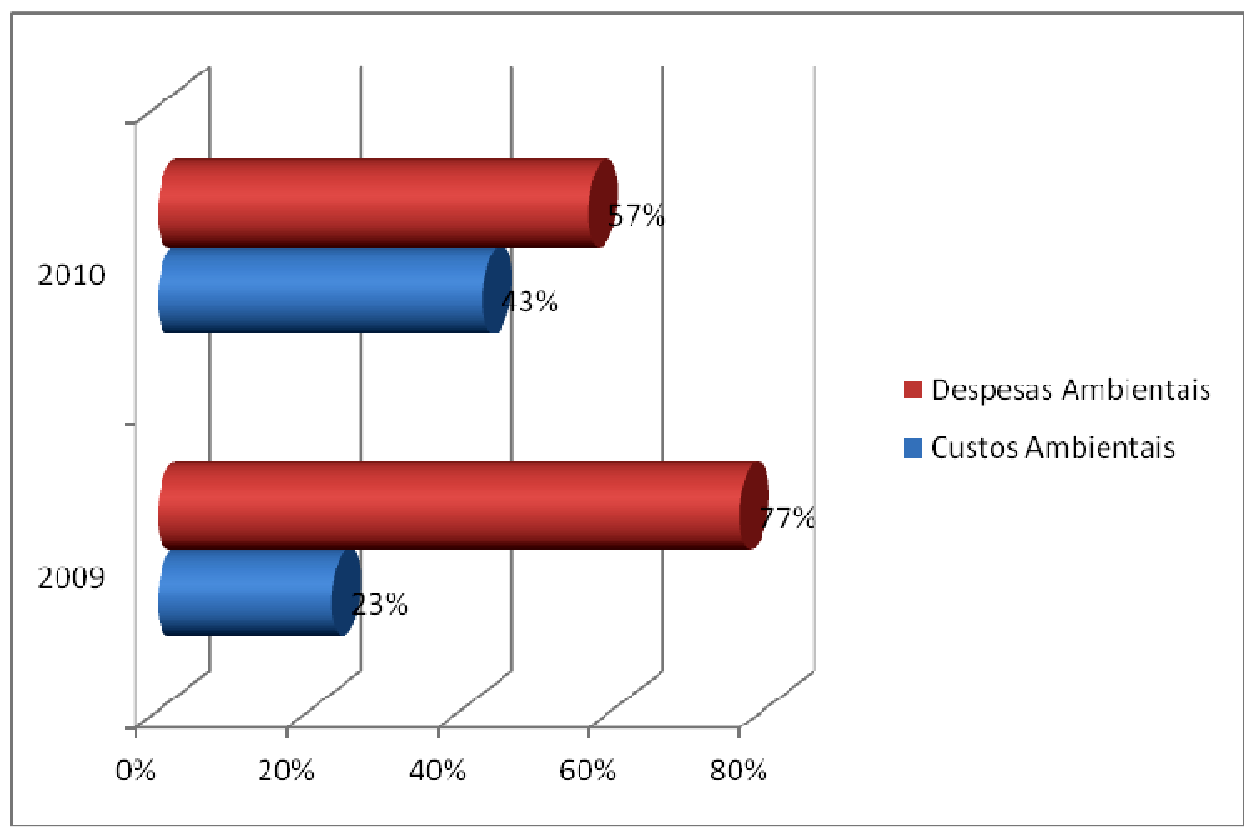

Figura 2. Gastos ambientais de 2009 e 2010 (Percentual em relação ao total dos Gastos). Fonte: Dados da pesquisa.

Sobre o Patrimônio da empresa, o percentual tanto das despesas ambientais como dos custos ambientais foram mais marcantes. As despesas ambientais, em 2009, representaram o percentual de 0,65\% em relação ao patrimônio e em 2010 foi de 0,44\%. Com isso, notou-se uma queda, ou seja, nesse intervalo de tempo, as despesas ambientais tiveram menos representatividade sobre o patrimônio do posto. Já com o custo ambiental ocorreu o inverso, houve um aumento de um ano para o outro de impacto sobre o patrimônio, com uma variação de 0,20\% em 2009 para 0,34\% em 2010. Isto deveu-se a um aumento relevante nos seguintes custos de um ano para o outro: manutenção das válvulas e suspiros dos tanques subterrâneos, recolhimento de resíduos, óleo queimado e embalagens de lubrificantes e análises laboratoriais da qualidade das águas subterrâneas.

Verificou-se então, um aumento dos custos ambientais e uma diminuição das despesas ambientais de um ano para o outro. Isso ocorreu devido a uma maior preocupação com manutenção e monitoramento dos equipamentos que interagem com o meio ambiente, o que acarreta acréscimo nos custos ambientais.

Dessa forma, constatou-se por meio da pesquisa, que houve uma representatividade negativa dos custos, gerando um efeito multiplicador, se analisado em conjunto com a receita, visto que o aumento dos custos não foi diluído no volume das receitas, uma vez essas diminuíram.

\section{CONSIDERAÇÕES FINAIS}

Este trabalho teve como objetivo principal identificar as medidas de gestão ambientais implantadas por um posto de combustíveis, além de analisar os impactos financeiros das medidas. Para tanto, foi realizado um levantamento junto à Cooperativa dos Condutores Autônomos de Veículos Rodoviários de Santa Maria/RS, com o intuito de pesquisar os gastos associados à adoção 
de medidas de gestão ambiental, tema de fundamental importância, frente ao anseio global por sustentabilidade.

Por meio da entrevista estruturada, identificaram-se os gastos com gestão ambiental inerentes à atividade, os quais foram classificados como custos ambientais e despesas ambientais, de acordo com literatura específica, regida pelas normas brasileiras de contabilidade.

O posto Coopaver está atento à qualidade dos produtos que comercializa e também ao correto armazenamento, transporte, manuseio e destino dos resíduos. Suas instalações estão de conformidade com as normas ambientais, o que garante a segurança de cooperados, clientes, colaboradores e comunidade. E ainda evita a contaminação do solo, da água e do ar.

Todos os resíduos produzidos como graxa, óleo, resíduos sólidos, lama, estopas, serragem e areia, usados na absorção de derrames, recipientes e embalagens são armazenados em local adequado e em seguida recolhidos por empresas de reciclagem. Notou-se que a empresa mantém atitudes proativas e reativas em relação à aplicação da legislação ambiental nas atividades cotidianas do posto.

Como atitude proativa, ou seja, medida ambiental adotada não por exigência legal, mas sim por opção, implantou-se o Livro de Movimentação de Combustíveis (LMC). Ferramenta essa, para monitoramento de vazamentos de combustíveis, baseado no pressuposto de que todo combustível que entra deve sair, caso o volume de saída de combustível seja inferior ao volume de entrada, pode haver vazamentos, que podem ser identificados em tempo hábil a fim de impedir maiores danos.

Os principais custos ambientais com manutenção das atividades de controle e preservação ambiental são: manutenção das válvulas e suspiros dos tanques subterrâneos, manutenção da caixa separadora de água e óleo e poços de monitoramento, manutenção das bombas eletrônicas de abastecimento e monitoramento dos tanques ecológicos, recolhimento de resíduos, óleo queimado e embalagens de lubrificantes e análises laboratoriais da qualidade das águas subterrâneas.

Em relação às despesas ambientais, foi constatado que consistem em taxas a órgãos públicos e taxas de alvarás ambientais.

Com isso constatou-se, que as despesas e os custos ambientais tiveram cada um a sua representatividade sobre o resultado econômico e financeiro e também sobre o patrimônio. As despesas não tiveram impactos significativos sobre o resultado, uma vez que comparadas aos custos, houve uma queda de 2009 para 2010, enquanto que os custos aumentaram nesse mesmo intervalo de tempo em relação ao Patrimônio Líquido. Logo, os custos impactaram negativamente o resultado do exercício da empresa por serem elevados e não diluídos pelo volume das receitas.

Constatou-se a importância da contabilidade e dos registros contábeis para a cooperativa, na identificação dos dados relacionados à preservação ambiental, pois permitem a identificação e quantificação clara das principais ações que podem ser tomadas em relação ao meio ambiente e à sustentabilidade, além de serem obtidas informações de caráter gerencial para uma melhor e mais precisa avaliação dos dados. O que, para a empresa, é de suma importância a fim de mantê-la atualizada com as exigências legais e contábeis em relação ao meio ambiente.

Foi de grande importância a colaboração e participação da Coopaver, em fornecer informações que permitiram o pleno desenvolvimento do trabalho, uma vez que houve total acessibilidade por parte da empresa em contribuir com informações e dados contábeis para a realização das análises necessárias. 


\section{REFERÊNCIAS}

BEUREN, Ilse Maria et al. Como elaborar trabalhos monográficos em contabilidade: teoria e prática. 3. ed. São Paulo: Atlas, 2006.

CERVO, Amado Luiz; BERVIAN, Pedro Alcino. Metodologia científica. 5. ed. São Paulo: Pearson Prentice Hall, 2002.

CONSELHO NACIONAL DO MEIO AMBIENTE (CONAMA). Resoluções: resolução $n^{\circ} 001$ de 23 de janeiro de 1986. [s.l.]: CONAMA, 1986. Disponível em:<http://www.ecologia.dbi.ufla.br/site\%20ecoaplicada/legisla\%C3\%A7\%C3\%A3o/Resolu\%C3\%A7\%C3\%A 30\%20CONAMA\%20N\%C2\%BA\%2001-1986.htm>. Acesso em: 01 nov. 2010.

. Resoluções: resolução $n^{\circ} 237$ de 19 de dezembro de 1997. [s.I.]: CONAMA, 1997. Disponível em: <http://www.mma.gov.br/port/conama/res/res97/res23797.html>. Acesso em: 20 out. 2010.

Resoluções: resolução $n^{\circ} 273$ de 29 de novembro de 2000. [s.I.]: CONAMA, 2000. Disponível em: <http://www.mma.gov.br/port/conama/res/res00/res27300.html>. Acesso em: 20 out. 2010.

GIL, Antônio Carlos. Como elaborar projetos de pesquisa. 4. ed. São Paulo: Atlas, 2007.

LORENZETT, Daniel Benitti; ROSSATO, Marivane Vestena; NEUHAUS, Mauricio. A gestão ambiental em postos de combustíveis. In: SIMPOSIO DE ENSINO PESQUISA E EXTENSÃO,10 a 12 de Nov. 2010, Santa Maria/RS. Anais eletrônicos... Santa Maria: SEPE, 2010. Disponível em: <http://www.unifra.br/eventos/sepe2010/2010/Trabalhos/sociais_Aplicadas/Completo/4642.pdf>. Acesso em: 20 nov. 2010.

MARCONI, Maria de Andrade; LAKATOS, Eva Maria. Fundamentos de metodologia científica. 2. ed. São Paulo: Atlas, 2005.

TINOCO, João Eduardo Prudêncio; KRAEMER, Maria Elisabeth Pereira. Contabilidade e gestão ambiental. São Paulo: Atlas, 2004. 